\title{
Renoprotective, anti-oxidative and anti-apoptotic effects of oral low-dose quercetin in the C57BL/6J model of diabetic nephropathy
}

Isabele BS Gomes ${ }^{1}$, Marcella L Porto ${ }^{2}$, Maria Carmen LFS Santos ${ }^{3}$, Bianca P Campagnaro ${ }^{3}$, Thiago MC Pereira ${ }^{3}$, Silvana S Meyrelles ${ }^{2}$ and Elisardo C Vasquez ${ }^{2,3^{*}}$

\begin{abstract}
Background: Diabetic nephropathy (DN) is one of the major causes of end-stage renal disease in diabetic patients. Increasing evidence from studies in the rodents has suggested that this disease is associated with increased oxidative stress due to hyperglycemia. In the present study, we evaluated the renoprotective, anti-oxidative and anti-apoptotic effects of the flavonoid quercetin in C57BL/6J model of DN.

Methods: DN was induced by streptozotocin (STZ, $100 \mathrm{mg} / \mathrm{kg} /$ day, for 3 days) in adult C57BL/6J mice. Six weeks later, mice were divided into the following groups: diabetic mice treated with quercetin (DQ, $10 \mathrm{mg} / \mathrm{kg} / \mathrm{day}$, 4 weeks), diabetic mice treated with vehicle (DV) or non-treated non-diabetic (ND) mice.

Results: Quercetin treatment caused a reduction in polyuria ( 45\%) and glycemia ( 35\%), abolished the hypertriglyceridemia and had significant effects on renal function including, decreased proteinuria and high plasma levels of uric acid, urea and creatinine, which were accompanied by beneficial effects on the structural changes of the kidney including glomerulosclerosis. Flow cytometry showed a decrease in oxidative stress and apoptosis in DN mice.

Conclusion: Taken together, these data show that quercetin effectively attenuated STZ-induced cytotoxicity in renal tissue. This study provides convincing experimental evidence and perspectives on the renoprotective effects of quercetin in diabetic mice and outlines a novel therapeutic strategy for this flavonoid in the treatment of DN.
\end{abstract}

Keywords: Quercetin, Diabetic nephropathy, Oxidative stress, Apoptosis, Flavonoids

\section{Introduction}

Diabetic nephropathy (DN) is one of the most important microvascular complications of diabetes mellitus [1-3] and is the largest single cause of end stage renal disease $[4,5]$, that leads to a decrease in quality of life and an increased risk of mortality [6]. Recent data indicate that reactive oxygen species (ROS) play a pivotal role in the pathophysiology of DN [7-9]. Persistent hyperglycemia is the main determinant of initiation, promotion and sustentation of $\mathrm{DN}$ and it contributes to oxidative stress via

\footnotetext{
* Correspondence: evasquez@terra.com.br

${ }^{2}$ Department of Physiological Sciences, Laboratory of Translational

Physiology, Health Sciences Center, UFES, Vitoria, Brazil

${ }^{3}$ Pharmaceutical Sciences Graduate Program, Vila Velha University (UW), Vila Velha, ES, Brazil

Full list of author information is available at the end of the article
}

two major mechanisms, augmentation of ROS [7,10-13] and the attenuation of antioxidative mechanisms through glycation of antioxidant enzymes [1,12,14].

The development of experimental models of DN has provided a valid approach to characterize its pathogenesis and to create new possibilities for the diagnosis and treatment of this disease. In this regard, the pancreatic islet cell toxin streptozotocin (STZ) has been widely used to induce diabetes in rodents $[1,15,16]$, mainly in rat models. Likewise in rat models, the mouse has become attractive for the understanding of human diseases due to the similarities in physiology and to the advantage that its genome can be easily manipulated [17] to produce models of complex genetic diseases such as atherosclerosis [18-20], which is not commonly developed in rats. 
Although cumulative evidence suggests that increased oxidative stress may play a crucial role in the pathogenesis of DN [21,22], antioxidant therapy has shown conflicting results during the treatment of $\mathrm{DN}$ in diabetic patients [23]. Currently, only blockers of the renin-angiotensin system are chronically used; however, there are limitations of this mechanism [23,24] which justifies the search for effective and safer antioxidant candidates. The flavonoids are plant phenolic compounds that exhibit strong antioxidant properties and are widely distributed throughout the plant kingdom; thus, flavonoids are a therapeutic option [25,26].

Quercetin is a bioflavonoid found in red wine and numerous fruits, vegetables, and nuts $[27,28]$. Recently, biochemical and pharmacological studies of quercetin have shown that it is a potent scavenger of ROS and possibly reduces the risk of cardiovascular and renal diseases [1,28-30]. However, its effects on kidney function, excessive ROS production and kidney cell apoptosis, that are supposed to occur in this mouse model of DN, have not yet been evaluated. Therefore, the present study was designed to test the hypothesis that quercetin presents nephroprotective effects on the main parameters that characterize the $\mathrm{DN}$. We focused our model in the C57BL/6J, which has been the most used genetic background mouse [18-20] but not yet investigated as a model of DN.

\section{Materials and methods \\ Animals}

Eight-week-old homozygous C57BL/6J mice were obtained from the Laboratory of Translational Physiology, Health Sciences Center, at the Federal University of Espirito Santo, Brazil. Animals were housed at room temperature $\left(22^{\circ} \mathrm{C}\right)$ in a humidity-controlled environment with a 12 -h light/12-h dark cycle in the Experimental Unit of the Laboratory of Translational Physiology. Mice were allowed free access to water and a standard laboratory chow diet (Labina ${ }^{\circ}$ ) until experiments were performed. The animals were studied according to the principles devised by the National Institute of Health (NIH) Guide for the Care and Use of Laboratory Animals and the protocol was previously approved by the Institutional Ethics Committee for the Use of Animals (CEUA, Protocol \# 013/2010).

\section{Experimental protocol}

Mice were rendered diabetic by intraperitoneal injection of STZ (Boehringer-Mannheim, Mannheim, Germany) diluted in citrate buffer (10 mM, pH 4.5) at a dose of $100 \mathrm{mg} / \mathrm{kg} /$ day for 3 days, The control group (non-diabetic, $\mathrm{ND}, \mathrm{n}=10$ ) was administered an equivalent volume of the vehicle citrate buffer. One week after STZ injection, glycemia was measured after 6 hours of food deprivation and animals with glucose levels greater than
$250 \mathrm{mg} / \mathrm{dL}$ for at least 2 days were considered diabetic. Six weeks after STZ injections, diabetic mice were randomly divided and received either no treatment (vehicle soy oil, $\mathrm{DV}, \mathrm{n}=10)$ or oral quercetin $(\mathrm{DQ}, \mathrm{n}=10)$ at a dosage of $10 \mathrm{mg} / \mathrm{kg}$ per day for 4 weeks. This dosage was based on previous studies with hypertensive and diabetic animals [31,32].

\section{Metabolic and biochemical parameters}

After STZ injection, all animals were weighed once a week. At week 4, the animals were housed for a 24-hour period in individual metabolic cages for adaptation. Following this period, a known volume of water and quantify of food were placed in the drinking bottles and the feeder, respectively. After 24 hours, the volume of liquid and chow remaining in the cages were measured. Urine was collected and its volume and protein concentration was determined. Animals were euthanized via an overdose of thiopental (Cristalia, Sao Paulo, Brazil, $200 \mathrm{mg} / \mathrm{kg}$, i.p.) after a period of food deprivation, and their blood was collected for glucose, creatinine, cholesterol, triglycerides, urea and uric acid measurements using colorimetric kits. Proteinuria was determined by a Bradford assay [33]. Tissues were perfused with cold phosphate-buffered saline (PBS, pH 7.4, $0.1 \mathrm{~mol} / \mathrm{L}$ ) through the left ventricle and the kidney was fixed in Duboscq-Brazil solution for histological evaluation.

\section{Kidney histology}

After perfusion, the mouse kidneys were rapidly fixed with Duboscq solution, weighed and processed for morphometric and histological analyses. Samples were dehydrated with a graded series of alcohols, embedded in paraffin, sectioned into $3-\mu \mathrm{m}$-thick slices and stained with hematoxylin and eosin for light microscopic morphological studies (AX70, Olympus, Center Valley, PA, USA). Images were captured at a 40x magnification with a color video camera (VKC150, Hitachi, Tokyo, Japan) connected to a microscope (AX70, Olympus, Center Valley, PA, USA). All morphometric and histological analysis were performed in a blinded manner. The mean glomerular tuft area of each kidney was obtained by calculating the mean value of 30 individual glomeruli measured by Image J software (version 1.33u, Public Domain). Masson's trichrome staining was used to quantify glomerulosclerosis. A total of 30 glomeruli were used to calculate the percentage of the stained area for each kidney using the Image J program (Public Domain Image Processing Program, National Institutes of Health, Bethesda, MD).

\section{Measurement of intracellular superoxide anions by flow cytometry}

Fractions enriched for kidney cell were obtained from each of the groups, were prepared based on previous 
studies and standardized in our laboratory. The kidney was grossly minced using surgical scissors and was incubated in an isolation solution containing collagenase type II (Gibco Life Technologies, Sao Paulo, SP, Brazil) to dissociate the cells. The cell suspension was filtered through a nylon screen (BD Falcon $70 \mu \mathrm{m}$ ) to remove cellular debris. The samples were then washed twice in PBS before further analysis. Dihydroethidium (DHE, $160 \mu \mathrm{M}$ ) was added to cell suspensions $\left(10^{6}\right.$ cells) which were then incubated at $37^{\circ} \mathrm{C}$ for $30 \mathrm{~min}$ in the dark in order to determine the intracellular production of superoxide anions $\left(\bullet \mathrm{O}_{2}{ }^{-}\right)$[34-36]. DHE is freely permeable to cells and is rapidly oxidized to ethidium, which binds to DNA and results in the amplification of a red fluorescence signal. Samples were treated with $10 \mathrm{mM}$ doxorubicin for $5 \mathrm{~min}$ to induce oxidative stress in the absence of cell toxicity; these samples served as positive control. Cells incubated with ethanol served as the negative control. Cells were then washed, resuspended in PBS, and maintained on ice for immediate detection via flow cytometry (FACSCanto II, Becton Dickinson, San José, CA, USA). Data were analyzed using FACSDiva software (BD Company), and overlay histograms were constructed using FCS Express software. For DHE fluorescence quantification, samples were acquired in duplicate, and 10,000 events were obtained for each measurement. Red fluorescence was detected between 564 and $606 \mathrm{~nm}$ using a 585/42 bandpass filter. Data are expressed as the geometric mean fluorescence intensity.

\section{Apoptosis}

Apoptotic kidney cells were quantified via annexin Vfluorescein isothiocyanate (FITC) and propidium iodide (PI) staining, using a commercial detection kit (Becton Dickinson, San José, CA, USA). Briefly, renal cells were washed twice with PBS and the final volume was adjusted to $500 \mu \mathrm{l}$ with binding buffer $\left(5 \times 10^{5}\right.$ cells). Then, $2 \mu \mathrm{l}$ of annexin V-FITC and $2 \mu \mathrm{L}$ of PI were added to the solution and the cells were gently vortexed. Cells were then incubated for $15 \mathrm{~min}$ at room temperature $\left(25^{\circ} \mathrm{C}\right)$ in the dark. Finally, cells were analyzed using a FACSCanto II flow cytometer (BD). Apoptosis was quantified by analysis of the flow cytometry data after annexin V-FITC and PI labeling.

Kidney cells that were annexin $\mathrm{V}-\mathrm{FITC}^{-} / \mathrm{PI}^{+}$were classified as damaged (Q1). Cells that were annexin V-FITC ${ }^{+} / \mathrm{PI}^{+}$ were considered to be late apoptotic or secondary apoptotic cells $(\mathrm{Q} 2)$. Cells that were annexin $\mathrm{V}-\mathrm{FITC}^{-} / \mathrm{PI}^{-}$were considered live cells (Q3). Cells that were annexin $\mathrm{V}-\mathrm{FITC}^{+} /$ $\mathrm{PI}^{-}$were classified as early or primary apoptotic cells (Q4) [37].

\section{Statistical analysis}

All data are expressed as the means \pm SEM. The Kolmogorov-Smirnov test showed that variables had a normal (Gaussian) distribution. Flow cytometry data of ROS production are expressed as the geometric MFIvariation coefficient of two repeated and statistically reproducible measurements of at least 5 independent animals (the Friedman test). The statistical analysis was performed by one-way analysis of variance (ANOVA). When the ANOVA showed significant differences, the Tukey's test was applied as a post hoc analysis. The differences were considered significant when $\mathrm{p}<0.05$.

\section{Results}

\section{Metabolic parameters}

Figure 1 summarizes the general physical characteristics, diuresis, and food and water intake, 10 weeks after the induction of diabetes. Diabetic mice exhibited hyperphagia $(5.0 \pm 0.5 \mathrm{~g} /$ day, Figure $1 \mathrm{~A})$ and polydipsia $(25 \pm 2 \mathrm{~mL} /$ $24 \mathrm{~h}$, Figure $1 \mathrm{~B})$ when compared to non-diabetic mice $(3.0 \pm 0.26 \mathrm{~g} /$ day and $5.0 \pm 0.6 \mathrm{~mL} / 24 \mathrm{~h})$. Quercetin treatment did not show a significant effect on food and water intake. Diabetic mice exhibited a severe polyuria $(24 \pm$ $2 \mathrm{~mL} / 24 \mathrm{~h}$, Figure 1D) when compared to non-diabetic mice $(1.9 \pm 0.2 \mathrm{~mL} / 24 \mathrm{~h})$, and this parameter was reduced by approximately $46 \%$ in diabetic mice treated with quercetin. Body weight was similar among the 3 groups; however, over the 2-week period, body weight gain in the nondiabetic group $(28 \% \mathrm{~g}, \mathrm{p}<0.05)$ neither the diabetic mice nor the diabetic mice treated with quercetin exhibited significant body weight gain $(+0.6 \pm 1.2$ and $+1.2 \pm 1.0$ g, respectively, Figure $1 C$ ).

\section{Biochemical parameters}

As expected, the results summarized in Figure 2 show that diabetic mice exhibited a significant increase in plasma glucose (3-fold), total cholesterol (1.7-fold) and triglycerides (1.7-fold) levels when compared to non-diabetic mice $(135 \pm 9 \mathrm{mg} / \mathrm{dL}, 78 \pm 2 \mathrm{mg} / \mathrm{dL}$ and $64 \pm 6 \mathrm{mg} / \mathrm{dL}$, respectively). Treatment with quercetin caused a significant attenuation of plasma hyperglycemia (35\%) and failed to reverse the hypercholesterolemia; however, it diminished the hypertriglyceridemia to levels of $34 \pm 6 \mathrm{mg} / \mathrm{dL}$, which was $50 \%$ lower than levels observed in the non-diabetic mice.

\section{Renal function parameters}

Figure 3 summarizes the mean values of the parameters used as indices of renal function. Diabetic mice exhibited significantly high plasma concentrations of uric acids ( $\sim 3$-fold, Figure $3 \mathrm{~A})$, urea (25\%, Figure $3 \mathrm{~B})$ and creatinine $(42 \%$, Figure $3 \mathrm{C})$ when compared to non-diabetic animals $(0.6 \pm 0.15 \mathrm{mg} / \mathrm{dL}, 70 \pm 3.00 \mathrm{mg} / \mathrm{dL}$ and $0.24 \pm$ $0.02 \mathrm{mg} / \mathrm{dL}$, respectively, $\mathrm{p}<0.05)$. Quercetin showed a tendency to reduce the hyperuricemia and significantly reduced the levels of plasma creatinine and urea levels to values similar to those observed in the non-diabetic group 
A

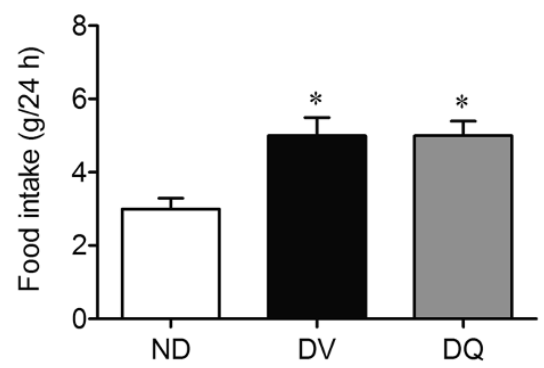

C

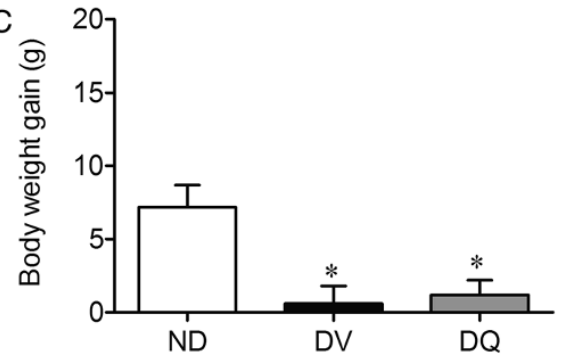

B

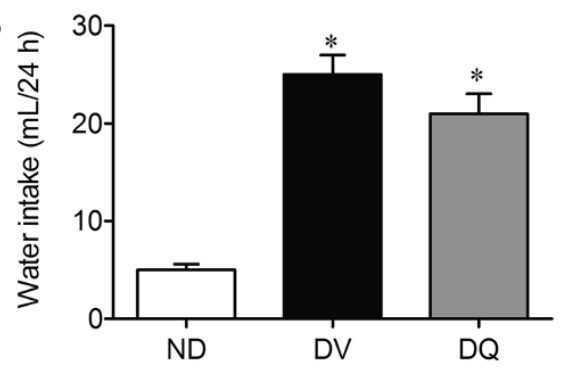

$\mathrm{D}$ 卫

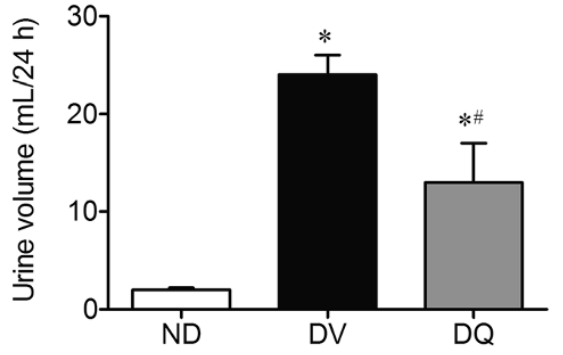

Figure 1 Food (A) and water (B) intake, body weight gain (C) and urine volume (D) in diabetic mice treated with quercetin (DQ) compared to diabetic mice administered vehicle (DV) and non-diabetic (ND) mice. Values are means \pm SEM for $n=6-8$ mice per group. ${ }^{*} p<0.05 \mathrm{vs}$. ND, $\# p<0.05$ vs. DV.

(Figure $3 \mathrm{C}$ ). Clearance of creatinine was $225 \pm 28 \mu \mathrm{L} / \mathrm{min}$ in non-diabetic mice and was significantly reduced in diabetic mice (34\%); however, creatinine clearance returned to normal levels upon treatment with quercetin (Figure 3E). Proteinuria, which is another index of renal function, was significantly increased ( 3 -fold, $\mathrm{p}<$ 0.05 , Figure $1 \mathrm{D})$ in the diabetic mice when compared to non-diabetic mice $(4.0 \pm 0.4 \mathrm{mg} / 24 \mathrm{~h}, \mathrm{p}<0.05)$. Treatment with quercetin tended to reduce levels of proteinuria, but these levels were still significantly higher than those observed for non-diabetic mice (Figure 3D).

\section{Kidney morphometric parameters}

Diabetes was associated with an increase of approximately $18 \%$ in kidney weight/body weight ratio when compared to non-diabetic mice $(13.2 \pm 0.3 \mathrm{mg} / \mathrm{g}, \mathrm{p}<0.05)$, whereas quercetin attenuated this diabetic effect (Figure 4A). The glomerular tuft area analysis of each kidney demonstrated a significant increase of approximately 30\% in diabetic mice when compared to non-diabetic mice and quercetin showed a tendency to attenuate this glomerular injury (Figure 4B). As illustrated in the typical photomicrographs (Figure 4D), glomerulosclerosis, appeared more often in the diabetic mice which was characterized by a deposition of extracellular matrix in the mesangium and by glomerular hyperplasia, was more important in the diabetic than in the non-diabetic mice and quercetin had a beneficial effect on this parameter (4C). On average, diabetic animals showed a significant increase in the glomerular tuff area $(30 \%, \mathrm{p}<0.05)$ and in the occurrence of glomerulosclerosis $(\sim 3$-fold, $\mathrm{p}<0.05)$ when compared to the non-diabetic mice $\left(2517 \pm 124 \mu^{2}\right.$ and $23 \pm 1.2 \%$, respectively), and diabetic mice treated with quercetin showed values similar to those observed in nondiabetic mice.

\section{Oxidative stress}

We evaluated ROS production using flow cytometry and DHE to quantify the generation of superoxide anions $\left(\bullet \mathrm{O}_{2}{ }^{-}\right)$; the presence of this compound is indicated by
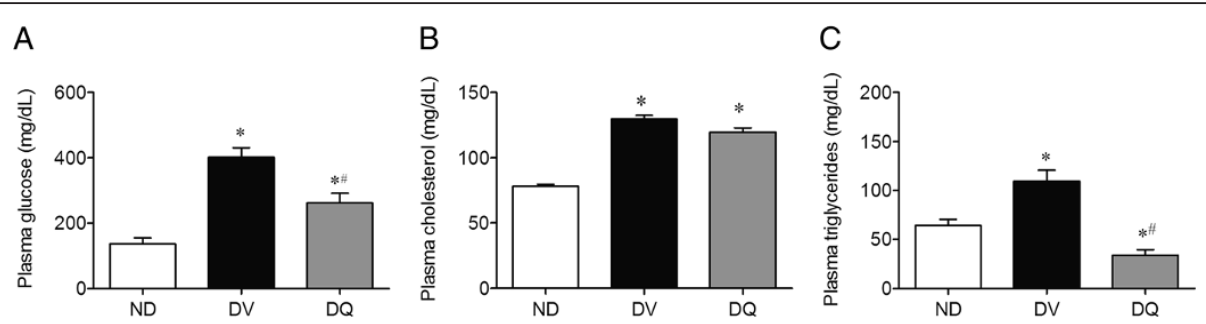

Figure 2 Plasma glucose (A), total cholesterol (B) and triglycerides (C) in diabetic mice treated with quercetin (DQ) compared to diabetic mice administered vehicle (DV) and non-diabetic (ND) mice. Values are means \pm SEM for $n=6-8$ mice per group. ${ }^{*} p<0.05$ vs. ND, ${ }^{\#} p<0.05$ vs. DV. 


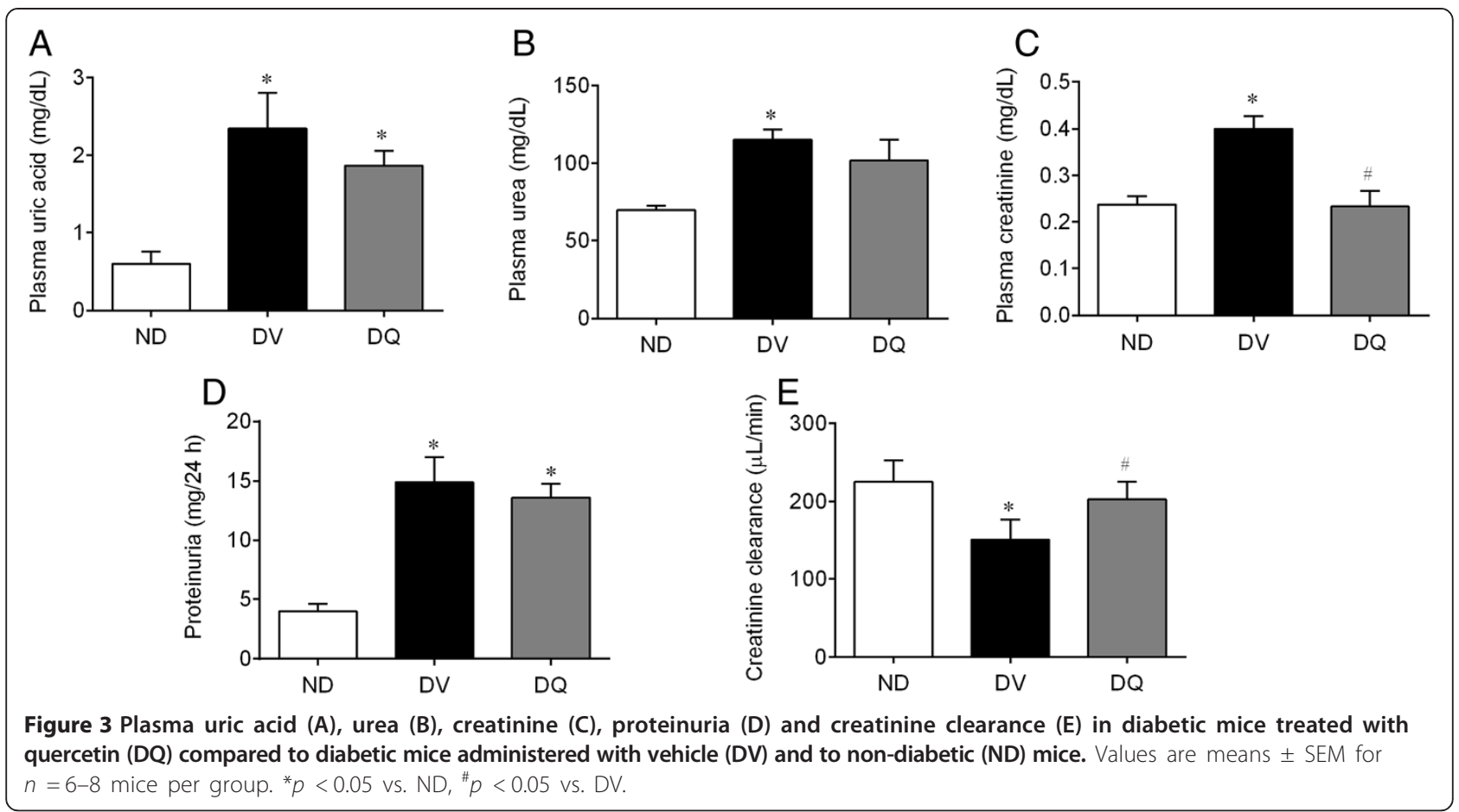

the geometric mean fluorescence intensity (in a.u.). Typical histograms obtained via flow cytometry analysis show a rightward-shift in the log DHE fluorescence in diabetic mice (Figure 5A) when compared to non-diabetic mice and diabetic mice treated with quercetin. As summarized in Figure $5 \mathrm{~B}$, we observed a remarkable increase in the levels of $\bullet \mathrm{O}_{2}{ }^{-}$in DV animals (56\%) when compared to ND mice $(1524 \pm 81$ a.u., $\mathrm{p}<0.05)$. Quercetin treatment significantly reduced the levels of oxidative stress to levels similar to those observed in ND mice.

\section{Apoptosis}

One aim of this study was to evaluate the viability of kidney cells using PI and annexin V staining via flow cytometry analysis. Although the percentage of viable kidney cells was significantly decreased in diabetic mice, greater than 95\% of the kidney cells obtained from the three groups of animals were viable which provided excellent conditions for the evaluation of apoptosis (Figure 6B). Typical histograms (Figure 6A) show that DV animals exhibited greater percentage of kidney cells in the early apoptosis quadrant (Q4: annexin $\left.\mathrm{V}^{+} / \mathrm{PI}^{-}\right)$, in the late apoptosis quadrant $(\mathrm{Q} 2$ : annexin $\left.\mathrm{V}^{+} / \mathrm{PI}^{+}\right)$and in the damaged cell quadrant $(\mathrm{Q} 1$ : annexin $\left.\mathrm{V}^{-} / \mathrm{PI}^{+}\right)$. In contrast, the number of cells in the quadrants Q4, Q2 and Q1 was markedly reduced for mice treated with quercetin. Figure $6 \mathrm{C}$ summarizes the percentage of cells in early and late apoptosis. Diabetic animals (DV) showed a marked increase in the percentage of cells
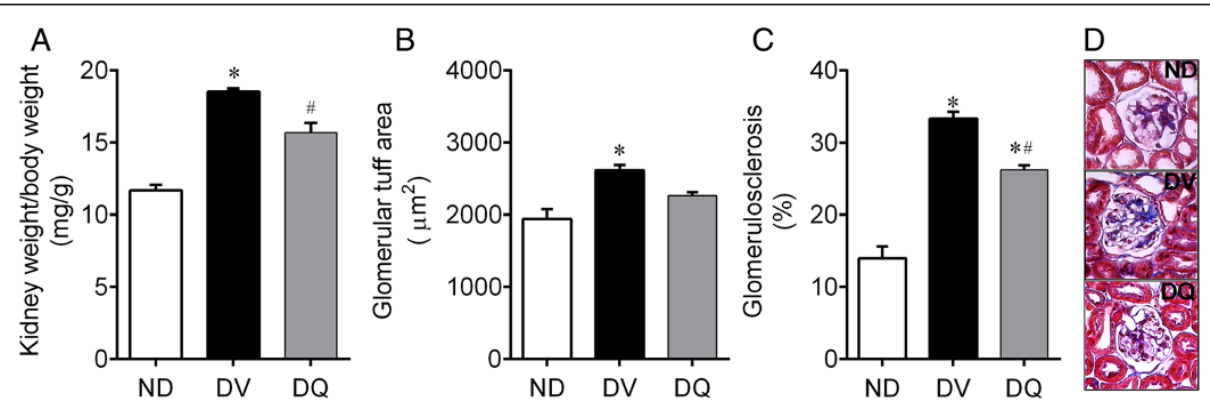

Figure 4 Kidney weight/body weight ratio (A), glomerular tuff area (B), glomerulosclerosis (C) in diabetic mice treated with quercetin (DQ) compared to diabetic mice administered with vehicle (DV) and non-diabetic (ND) mice. The mean value of 30 individual glomeruli areas from each kidney were used to calculate the glomerular tuff area and glomerulosclerosis. Micrographs (D) are representative glomerular sections (magnification of 400x) stained with Masson trichrome to identify sclerosis (blue) in each glomerulus. Values are means \pm SEM for $n=6-8$ mice per group. ${ }^{*} p<0.05$ vs. ND, ${ }^{\#} p<0.05$ vs. DV. 


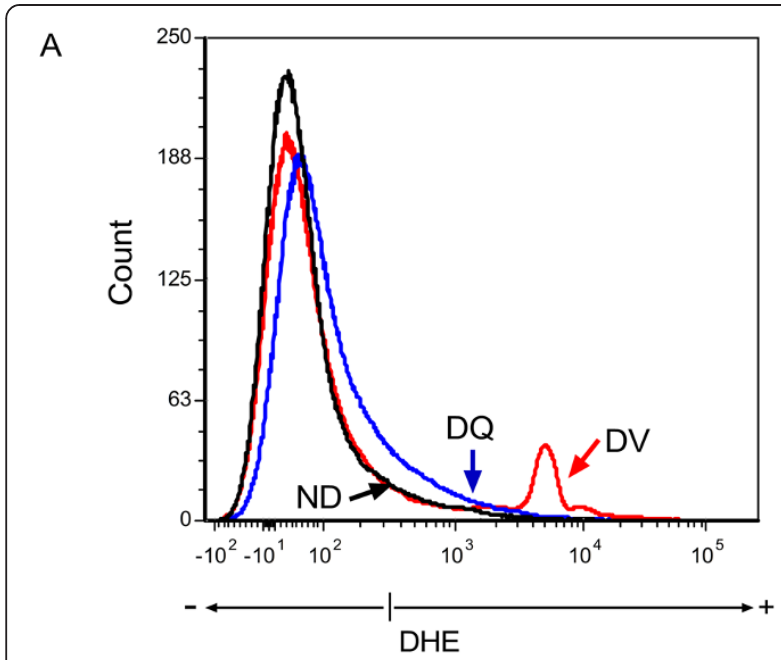

B

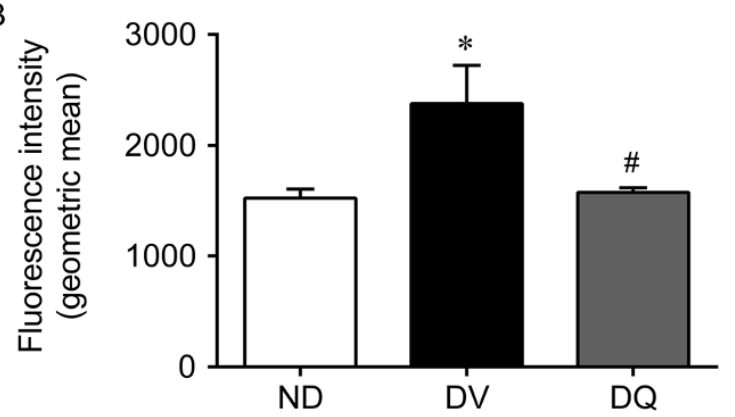

Figure 5 Production of superoxide anions. A: representative histograms from flow cytometry analysis using dihydroethidium (DHE) in diabetic mice treated with quercetin (DQ), compared to diabetic mice that received the vehicle (DV) and non-diabetic (ND) mice; the log fluorescence (X-axis) shows the intensity of fluorescence $(+)$ for the number of kidney cells assayed. B: bar graph shows geometric mean fluorescence intensity. ${ }^{*} p<0.05$ vs. ND group, ${ }^{\#} p<0.05$ vs. DV group.

in early (4-fold) and late apoptosis (6-fold) when compared to non-diabetic (ND) mice $(1.58 \pm 0.35 \%$ and $0.46 \pm$ $0.15 \%$, respectively). Treatment of diabetic (DV) mice with quercetin (DQ) had a marked effect on the progression from early to late apoptosis (Figure 6C). Quercetin treatment tended to reduce the high levels of early apoptosis, but quercetin was able to decrease the percentage values to levels similar to those observed in non-diabetic animals.

\section{Discussion}

This work showed that chronic oral treatment with lowdose quercetin exerts antidiabetic effects and attenuates the development of nephropathy in STZ-induced DN mice. These results are supported by a decrease of plasma glucose, creatinine, triglycerides, proteinuria and diminution of mesangial matrix expansion accompanied by a reduction in $\bullet \mathrm{O}_{2}{ }^{-}$production and apoptosis in kidney cells.

STZ-injected mice exhibit destruction of $\beta$ cells and reduction in insulin secretory capacity $[15,38]$. Consequently, these mice develop typical characteristics of diabetes such as polydipsia, polyuria, and proteinuria accompanied by loss of body weight (even with polyphagia) as observed in the present study. Furthermore, in accordance with our biochemical and morphological data, we considered the five stages of clinical classification of DN $[39,40]$ and suggest that this experimental murine model corresponds to a stage 4 clinical classification due to its declining glomerular filtration rate and proteinuria; thus, this model is suitable for evaluating the nephroprotective effects of the bioflavonoid quercetin. It must be noted that we avoided interfering with the intrinsic nephrotoxic effects of STZ by acquiring our data 6 weeks after STZ administration when the kidneys are known to have recovered from the acute renal injury caused by STZ $[38,41,42]$; thus, we can assume that the damages observed in our model was due only to diabetic status.

Interest in studies of the effects of natural antioxidants prevent oxidative damage in mouse models of diabetes has recently grown $[2,38,43]$. The best candidates are generally molecules that show high power antioxidant capacity, high permeability to mitochondrion [44], long half-lives [45] and enhancement of enzyme activity [43]; quercetin exhibits all of these traits. This bioflavonoid may inhibit the formation of ROS in the three different ways: (a) by interacting directly with $\bullet \mathrm{O}_{2}{ }^{-}$during initiation, (b) by forming hydroxyl radicals via the chelation of iron ions, and (c) by directly reacting with lipid peroxyl radicals scavengers during lipid peroxidation [46]. Additionally, it is possible that quercetin increases the activity of superoxide dismutase, catalase, glutathione peroxidase, glutathione reductase and glutathione [43,47]. All these effects may promote radical scavenging activity, anti-inflammatory and antiapoptotic effects and contribute to renal protection against STZ-induced DN.

Recent data has shown that the persistent hyperglycemia leads to an increase in the activity of several pathways involved in the disease that contribute to oxidative stress: (1) auto-oxidation of glucose, (2) advanced glycation end-product (AGE) formation, (3) polyol pathway flux, (4) protein kinase $\mathrm{C}$ (PKC) isoforms activation and (5) mitochondrial dysfunction [5,10,48-50]. Our results demonstrate that quercetin attenuates hyperglycemia in accordance with some authors [46,51-54], however, other authors disagree $[1,43]$. Independent of this apparent inconsistence, the impact on glycemia may be due to perturbations of some pathways. Previous studies have shown that this bioflavonoid can protect pancreatic $\beta$-cells from oxidative stress and damage (either directly or indirectly) and improve insulin secretion in STZ models [51,53]. Additionally, quercetin can stimulate glucose uptake in peripheral tissues via the translocation of GLUT4 $[46,55,56]$ and can increase hepatic glucokinase activity [53], thus augmenting both oxidation and storage of glucose and 

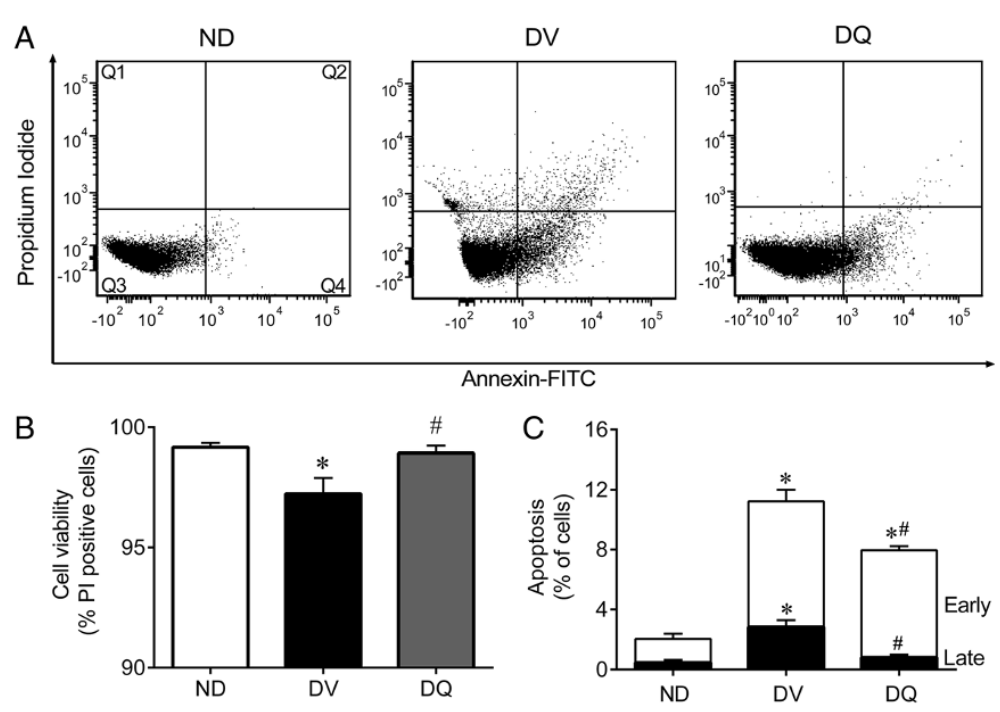

Figure 6 Flow cytometric analysis of apoptosis in kidney cells. Each dot plot (A) was constructed using propidium iodide (PI) and annexin V/FITC staining indicating: damaged cells (Q1), cells that are undergoing late apoptosis (Q2), viable cells (Q3) and cells in early apoptosis (Q4). Bar graph $\mathbf{B}$ shows the average percentage of PI positive (viable) cells, which were used to quantify apoptosis. Bar graph $\mathbf{C}$ shows the average percentage of cells in early and late apoptosis in non-diabetic mice (ND), diabetic mice administered vehicle (DV) and diabetic mice treated with quercetin (DQ). Values are mean \pm SEM for 6 to 8 animals per group. ${ }^{*} p<0.05$ vs. ND group and ${ }^{\#} p<0.05$ vs. DV group.

reducing hepatic gluconeogenesis and glycogenolysis [57]. Moreover, it has been reported that quercetin can blockade $\alpha$-glucosidase activity in vitro [57,58] and in vivo [53], thus inhibiting the digestion and absorption of carbohydrates in the small intestine [59]. In our study, this latter hypothesis provide a better explanation for the hypoglycemic effect exhibited by quercetin, considering that it exhibits low bioavailability via oral administration due to poor solubility and stability [25]. Therefore, we cannot discard the notion that indirect effects of quercetin on oxidative stress are responsible for the improvement in glycemic homeostasis, as recently observed in a mouse model by Alam et al. [56].

It has been shown that decreases in body weight are due to intense dehydration and catabolism of fats and proteins, even under the polyphagia and polydipsia evident conditions observed in the DN group [43,60]. This hypothesis is supported by the observation that hypertriglyceridemia and, in part, azotemia occurs in diabetic animals. Quercetin treatment was capable of reducing polyuria and fat and protein levels, likely as a consequence of better control of the glycemic state which leads to lower release of fatty acids from adipose tissue and normalizes triglycerides plasma levels without modifying the hypercholesterolemia; these results are similar to those observed by others [11]. It should be noted that, since this flavonoid may decrease LDL and increase HDL [61,62], we cannot discard the possibility of alteration in the ratio HDL/LDL, maintaining the hypercholesterolemia invariable. Moreover, the dose we used in the present study $(10 \mathrm{mg} / \mathrm{Kg})$ was unable to improve body weight, which conflicts with another report [43]. This apparent contradiction could be due to different types of experimental rodent models, the use of higher doses (from 2.5- to 10-fold) or the route of administration (e.g., intraperitoneal), which could increase the bioavailability of quercetin as observed by others [38,63-65].

Our data corroborate the hypothesis that links renal dysfunction to renal oxidative stress and is in agreement with other reports $[1,56]$. Under pathologic conditions of oxidative stress, the increased production of ROS could compromise NO bioavailability and promote the formation of a variety of vasoconstrictive mediators that could affect renal functions, such as tissue perfusion and glomerular filtration $[1,24,42]$. These changes could contribute to increases in serum creatinine, urea and uric acid, accompanied by a reduction of creatinine clearance and proteinuria, as observed by us and by others [66,67]. It is likely that the antioxidative properties of quercetin decreases the production of vasoactive autacoids, which may play a role in its improvement of renal dysfunction in diabetes. This hypothesis is further supported by reports that quercetin produce a direct vasorelaxant effect in vascular tissues [68-70]. Furthermore, the glomerulus is considerably more sensitive to oxidative injuries than other nephron segments [70]. This and the above factors could explain our finding regarding the improvement in creatinine clearance in the DN group treated with quercetin, despite the absence of the normalization of other renal parameters. It should be emphasized that urea and uric acid can be generated by amino acid and purine 
catabolism, respectively, and that both products are also excreted by tubular secretion $[66,67]$.

In addition to the biochemical parameters, our morphological data also demonstrate that quercetin exhibits a nephroprotective effect. In diabetic mice, we observed a significant increase in glomerular tuft size and glomerulosclerosis indicating an early diabetes-induced renal injury; these results are in agreement with other reports $[5,21,32,67,71]$. The novelty of the present study is that treatment with quercetin resulted in a significant amelioration of the observed glomerulosclerosis and the kidney weight/body weight ratio, most likely due to the hypoglycemic effect discussed above in addition to its direct antioxidative properties. Oxidative stress plays a major role in the disruption of cellular functions in the kidney and leads to increased vascular permeability and tissue damage [6]. This hypothesis is supported by the finding of others $[11,43]$ showing evidence of renal oxidative stress in diabetic rats [38,63-65].

In support of this oxidative stress hypothesis, flow cytometry assessment of dihydroethidium (DHE) fluorescence showed that the increased levels of $\bullet \mathrm{O}_{2}{ }^{-}$in the kidneys of diabetic mice was reduced by quercetin treatment and resulted in the abolishment of ROS (Figure 5). This finding corroborates the concept that the overproduction of $\bullet \mathrm{O}_{2}{ }^{-}$is implicated in the pathophysiology of diabetic nephropathy and that this flavonoid is a potent scavenger of ROS that could potentially reduce the risk of related diseases [29,30,46,54,56,72,73]. Moreover, oxidative stress is recognized as a strong mediator of apoptosis $[43,54,74]$. Our flow cytometry data show, for the first time that DN in this mouse model is accompanied by apoptosis, indicating a marked effect of this disease on kidney cell function. Interestingly, quercetin treatment was able to greatly ameliorate the onset of both early and late apoptosis in diabetic mice and to restore cell viability. Our data corroborate the findings of Liu et al. [75] who observed lower ROS production and apoptosis in kidneys damaged by lead when treated with the same bioflavonoid; these results are in agreement with others who reported that quercetin possesses anti-apoptotic properties [54,76,77]. In contrast, high levels of quercetin increased the number of dead kidney cells, indicating the presence of dose-dependent auto-oxidative activity followed by inhibition of mitochondrial respiration which affect ROS production $[43,78]$. Therefore, our data contribute to a better understanding about the potential use of quercetin as an antioxidant in a dose-dependent manner.

Although other studies have tested the effects of quercetin on the $\mathrm{DN}$ rat model, it should be considered that the common route of administration has been via intraperitoneal $[43,46,54,63]$. On the other hand when quercetin is administered via oral $[38,64,65]$, the dose has been much higher ( 25 to $100 \mathrm{mg} / \mathrm{Kg}$ ) than that we used in the genetic background C57BL/6J mouse. The importance of our data is that we found beneficial effects, including a decreased oxidative stress and anti-apoptotic effect, both detected by direct measurements, even using a lowest relative bioavailability oral dose of quercetin (10 $\mathrm{mg} / \mathrm{Kg}$ ). Thus, these additional data highlight the importance of quercetin as potential nutraceutical for management of $\mathrm{DN}$.

In conclusion, our results were obtained from the most commonly used mouse genetic background (C57BL/6J) and suggest that oxidative stress plays a pivotal role in the pathophysiology of DN and that oral low-dose quercetin exhibits a beneficial effect by ameliorating the consequences of hyperglycemia-induced ROS overproduction in the kidney. Thus, quercetin is a promising therapeutic agent that could potentially be used for the prevention and/or treatment of renal dysfunction caused by diabetes.

\section{Competing interests}

The authors declare that they have no competing interests.

\section{Authors' contributions}

IBSG contributed to the design of the study, carried out experimental analysis and acquisition of data, analysis and interpretation of the data and drafted the manuscript. MLP and BPC carried out the flow cytometry analysis for evaluation of oxidative stress and apoptosis. MCLFSS was the responsible for the histological analysis. TMCP participated in the critical revision of the manuscript. SSM participated in the design of the study and supervised the care and treatment of the groups of animals. ECV was the supervisor of the first author, the study's design, carried out the experimental analysis and critically reviewed the manuscript. All authors read and approved the final version of the manuscript.

\section{Acknowledgements}

ECV is supported by the National Council for the Development of Science and Technology (CNPq, Ref. 302582/2011-8 Grant). SSM is supported by the National Council for the Development of Science and Technology (CNPq, Ref. 305188/2012-7 Grant) and the State Agency for the Development of Science and Technology (FAPES/CNPq/PRONEX Edital 012/2009).

\section{Author details}

${ }^{1}$ Department of Pharmaceutical Sciences, Health Sciences Center, Federal University of Espirito Santo (UFES), Vitoria, Brazil. ${ }^{2}$ Department of Physiological Sciences, Laboratory of Translational Physiology, Health Sciences Center, UFES, Vitoria, Brazil. ${ }^{3}$ Pharmaceutical Sciences Graduate Program, Vila Velha University (UW), Vila Velha, ES, Brazil.

Received: 7 August 2014 Accepted: 29 November 2014 Published: 6 December 2014

\section{References}

1. Anjaneyulu M, Chopra K: Quercetin, an anti-oxidant bioflavonoid, attenuates diabetic nephropathy in rats. Clin Exp Pharmacol Physiol 2004, 31(4):244-248.

2. Lin CY, Yin MC: Renal protective effects of extracts from guava fruit (Psidium guajava L.) in diabetic mice. Plant Foods Hum Nutr 2012, 67(3):303-308

3. Aires Neto P, Gomes HV, Campos M: Management of hyperglycemia in patients with chronic kidney disease. J Nephrol 2013, 26(4):629-635.

4. Vallon V, Rose M, Gerasimova M, Satriano J, Platt KA, Koepsell H, Cunard R, Sharma K, Thomson SC, Rieg T: Knockout of Na-glucose transporter SGLT2 attenuates hyperglycemia and glomerular hyperfiltration but not kidney growth or injury in diabetes mellitus. Am J Physiol Renal Physiol 2013, 304(2):F156-F167.

5. Powell DW, Kenagy DN, Zheng S, Coventry SC, Xu J, Cai L, Carlson EC, Epstein PN: Associations between structural and functional 
changes to the kidney in diabetic humans and mice. Life Sci 2013, 93(7):257-264.

6. Brown W: Microvascular complications of diabetes mellitus: renal protection accompanies cardiovascular protection. Am J Cardiol 2008, 102(12A):10L-13L.

7. Brownlee M: Biochemistry and molecular cell biology of diabetic complications. Nature 2001, 414(6865):813-820.

8. Tan AL, Forbes JM, Cooper ME: AGE, RAGE, and ROS in diabetic nephropathy. Semin Nephrol 2007, 27(2):130-143.

9. Campbell KN, Raij L, Mundel P: Role of angiotensin II in the development of nephropathy and podocytopathy of diabetes. Curr Diabetes Rev 2011, 7(1):3-7.

10. Singh R, Kishore L, Kaur N: Diabetic peripheral neuropathy: current perspective and future directions. Pharmacol Res 2014, 80:21-35.

11. Ozcelik D, Tuncdemir M, Ozturk M, Uzun H: Evaluation of trace elements and oxidative stress levels in the liver and kidney of streptozotocin-induced experimental diabetic rat model. Gen Physiol Biophys 2011, 30(4):356-363.

12. Stanton RC: Oxidative stress and diabetic kidney disease. Curr Diab Rep 2011, 11(4):330-336

13. Tachibana H, Ogawa D, Sogawa N, Asanuma M, Miyazaki I, Terami N, Hatanaka T, Horiguchi CS, Nakatsuka A, Eguchi J, Wada J, Yamada H, Takei K, Makino $\mathrm{H}$ : Metallothionein deficiency exacerbates diabetic nephropathy in streptozotocin-induced diabetic mice. Am J Physiol Renal Physiol 2014, 306(1):F105-F115.

14. Marrazzo G, Barbagallo I, Galvano F, Malaguarnera M, Gazzolo D, Frigiola A D'Orazio N, Li Volti G: Role of dietary and endogenous antioxidants in diabetes. Crit Rev Food Sci Nutr 2014, 54(12):1599-1616.

15. Like AA, Rossini AA: Streptozotocin-induced pancreatic insulitis: new model of diabetes mellitus. Science 1976, 193(4251):415-417.

16. Tesch $\mathrm{GH}$, Allen TJ: Rodent models of streptozotocin-induced diabetic nephropathy. Nephrology (Carlton) 2007, 12(3):261-266.

17. Vasquez EC, Johnson RF, Beltz TG, Haskell RE, Davidson BL, Johnson AK: Replication-deficient adenovirus vector transfer of gfp reporter gene into supraoptic nucleus and subfornical organ neurons. Exp Neurol 1998 154(2):353-365.

18. Vasquez EC, Peotta VA, Gava AL, Pereira TM, Meyrelles SS: Cardiac and vascular phenotypes in the apolipoprotein E-deficient mouse. J Biomed Sci 2012, 19:22.

19. Nogueira BV, Peotta VA, Meyrelles SS, Vasquez EC: Evaluation of aortic remodeling in apolipoprotein E-deficient mice and renovascular hypertensive mice. Arch Med Res 2007, 38(8):816-821.

20. Pereira TM, Nogueira BV, Lima LC, Porto ML, Arruda JA, Vasquez EC, Meyrelles SS: Cardiac and vascular changes in elderly atherosclerotic mice: the influence of gender. Lipids Health Dis 2010, 19(9):87.

21. Breyer MD, Böttinger E, Brosius FC 3rd, Coffman TM, Harris RC, Heilig CW Sharma K, AMDCC: Mouse models of diabetic nephropathy. J Am SoC Nephrol 2005, 16(1):27-45.

22. Brosius FC 3rd, Alpers CE: New targets for treatment of diabetic nephropathy: what we have learned from animal models. Curr Opin Nephrol Hypertens 2013, 22(1):17-25.

23. Tavafi M: Diabetic nephropathy and antioxidants. J Nephropathol 2013 , 2(1):20-27.

24. Cooper ME: Interaction of metabolic and haemodynamic factors in mediating experimental diabetic nephropathy. Diabetologia 2001, 44(11):1957-1972.

25. Cai X, Fang Z, Dou J, Yu A, Zhai G: Bioavailability of quercetin: problems and promises. Curr Med Chem 2013, 20(20):2572-2582.

26. Pérez-Gregorio MR, Regueiro J, Simal-Gándara J, Rodrigues AS, Almeida DP: Increasing the added-value of onions as a source of antioxidant flavonoids: a critical review. Crit Rev Food Sci Nutr 2014, 54(8):1050-1062.

27. Olson ER, Melton T, Dong Z, Bowden GT: Stabilization of quercetin paradoxically reduces its proapoptotic effect on UVB-irradiated human keratinocytes. Cancer Prev Res (Phila) 2008, 1(5):362-368.

28. Perez-Vizcaino F, Duarte J, Jimenez R, Santos-Buelga C, Osuna A: Antihypertensive effects of the flavonoid quercetin. Pharmacol Rep 2009, 61(1):67-75

29. Bischoff SC: Quercetin: potentials in the prevention and therapy of disease. Curr Opin Clin Nutr Metab Care 2008, 11(6):733-740.

30. Coqueiro A, Regasini LO, Skrzek SC, Queiroz MM, Silva DH, da Silva Bolzani V: Free radical scavenging activity of Kielmeyera variabilis Clusiaceae). Molecules 2013, 18(2):2376-2385.
31. Machha A, Mustafa MR: Chronic treatment with flavonoids prevents endothelial dysfunction in spontaneously hypertensive rat aorta. J Cardiovasc Pharmacol 2005, 46(1):36-40.

32. Ajay M, Achike FI, Mustafa AM, Mustafa MR: Effect of quercetin on altered vascular reactivity in aortas isolated from streptozotocin-induced diabetic rats. Diabetes Res Clin Pract 2006, 73(1):1-7.

33. Bradford MM: A rapid and sensitive method for the quantitation of microgram quantities of protein utilizing the principle of protein-dye binding. Anal Biochem 1976, 72:248-254.

34. Campagnaro BP, Tonini CL, Nogueira BV, Casarini DE, Vasquez EC, Meyrelles SS: DNA damage and augmented oxidative stress in bone marrow mononuclear cells from Angiotensin-dependent hypertensive mice. Int J Hypertens 2013, 2013:305202.

35. Rodrigues BP, Campagnaro BP, Balarini CM, Pereira TM, Meyrelles SS, Vasquez EC: Sildenafil ameliorates biomarkers of genotoxicity in an experimental model of spontaneous atherosclerosis. Lipids Health Dis 2013, 28(12):128.

36. Dias AT, Rodrigues BP, Porto ML, Gava AL, Balarini CM, Freitas FP, Palomino Z, Casarini DE, Campagnaro BP, Pereira TM, Meyrelles SS, Vasquez EC: Sildenafil ameliorates oxidative stress and DNA damage in the stenotic kidneys in mice with renovascular hypertension. J Trans/ Med 2014, 6(12):35.

37. Monga J, Pandit S, Chauhan RS, Chauhan CS, Chauhan SS, Sharma M: Growth inhibition and apoptosis induction by (+)-Cyanidan-3-ol in hepatocellular carcinoma. PLoS One 2013, 8(7):e68710.

38. Wang C, Pan Y, Zhang QY, Wang FM, Kong LD: Quercetin and allopurinol ameliorate kidney injury in STZ-treated rats with regulation of renal NLRP3 inflammasome activation and lipid accumulation. PLoS One 2012, 7(6):e38285.

39. Mogensen CE, Christensen CK, Vittinghus E: The stages in diabetic renal disease. With emphasis on the stage of incipient diabetic nephropathy. Diabetes 1983, 32(Suppl 2):64-78.

40. Jerums G, Panagiotopoulos S, Premaratne E, Maclsaac RJ: Integrating albuminuria and GFR in the assessment of diabetic nephropathy. Nat Rev Nephrol 2009, 5(7):397-406.

41. Kraynak AR, Storer RD, Jensen RD, Kloss MW, Soper KA, Clair JH, DeLuca JG, Nichols WW, Eydelloth R: Extent and persistence of streptozotocin-induced DNA damage and cell proliferation in rat kidney as determined by in vivo alkaline elution and BrdUrd labeling assays. Toxicol Appl Pharmacol 1995, 135(2):279-286.

42. Ortega A, Fernández A, Arenas MI, López-Luna P, Muñóz-Moreno C, Arribas I, Olea N, García-Bermejo L, Lucio-Cazana J, Bosch RJ: Outcome of acute renal injury in diabetic mice with experimental endotoxemia: role of hypoxia-inducible factor-1 a. J Diabetes Res 2013, 2013:254529.

43. Oršolić N, Gajski G, Garaj-Vrhovac V, Dikić D, Prskalo ZŠ, Sirovina D DNA-protective effects of quercetin or naringenin in alloxan-induced diabetic mice. Eur J Pharmacol 2011, 656(1-3):110-118.

44. Ortega R, García N: The flavonoid quercetin induces changes in mitochondrial permeability by inhibiting adenine nucleotide translocase. J Bioenerg Biomembr 2009, 41(1):41-47.

45. Sesink AL, O'Leary KA, Hollman PC: Quercetin glucuronides but not glucosides are present in human plasma after consumption of quercetin-3-glucoside or quercetin-4'-glucoside. J Nutr 2001, 131(7):1938-1941.

46. Pereira Braga C, Momentti AC, Barbosa Peixoto F, de Fátima Ferreira Baptista R, dos Santos FA, Fava FH, Fernandes AA: Influence of treatment with quercetin on lipid parameters and oxidative stress of pregnant diabetic rats. Can J Physiol Pharmacol 2013, 91(2):171-177.

47. Molina MF, Sanchez-Reus I, Iglesias I, Benedi J: Quercetin, a flavonoid antioxidant, prevents and protects against ethanol-induced oxidative stress in mouse liver. Biol Pharm Bull 2003, 26(10):1398-1402.

48. Du XL, Edelstein D, Dimmeler S, Ju Q, Sui C, Brownlee M: Hyperglycemia inhibits endothelial nitric oxide synthase activity by posttranslational modification at the Akt site. J Clin Invest 2001, 108(9):1341-1348.

49. Moreira PI, Rolo AP, Sena C, Seiça R, Oliveira CR, Santos MS: Insulin attenuates diabetes-related mitochondrial alterations: a comparative study. Med Chem 2006, 2(3):299-308.

50. Blake R, Trounce IA: Mitochondrial dysfunction and complications associated with diabetes. Biochim Biophys Acta 2014, 1840(4):1404-1412.

51. Vessal M, Hemmati $M$, Vasei $M$ : Antidiabetic effects of quercetin in streptozocin-induced diabetic rats. Comp Biochem Physiol C Toxicol Pharmacol 2003, 135C(3):357-364. 
52. Kobori M, Masumoto S, Akimoto Y, Takahashi Y: Dietary quercetin alleviates diabetic symptoms and reduces streptozotocin-induced disturbance of hepatic gene expression in mice. Mol Nutr Food Res 2009, 53(7):859-868.

53. Kim JH, Kang MJ, Choi HN, Jeong SM, Lee YM, Kim J: Quercetin attenuates fasting and postprandial hyperglycemia in animal models of diabetes mellitus. Nutr Res Pract 2011, 5(2):107-111.

54. Kanter M, Aktas C, Erboga M: Protective effects of quercetin against apoptosis and oxidative stress in streptozotocin-induced diabetic rat testis. Food Chem Toxicol 2012, 50(3-4):719-725.

55. Xu M, Hu J, Zhao W, Gao X, Jiang C, Liu K, Liu B, Huang F: Quercetin differently regulates insulin-mediated glucose transporter 4 translocation under basal and inflammatory conditions in adipocytes. Mol Nutr Food Res 2014, 58(5):931-941.

56. Alam MM, Meerza D, Naseem I: Protective effect of quercetin on hyperglycemia, oxidative stress and DNA damage in alloxan induced type 2 diabetic mice. Life Sci 2014, 109(1):8-14.

57. Sarkhail P, Rahmanipour S, Fadyevatan S, Mohammadirad A, Dehghan G, Amin G, Shafiee A, Abdollahi M: Antidiabetic effect of Phlomis anisodonta: effects on hepatic cells lipid peroxidation and antioxidant enzymes in experimental diabetes. Pharmacol Res 2007, 56(3):261-266.

58. Ishikawa A, Yamashita H, Hiemori M, Inagaki E, Kimoto M, Okamoto M, Tsuji H, Memon AN, Mohammadio A, Natori Y: Characterization of inhibitors of postprandial hyperglycemia from the leaves of Nerium indicum. J Nutr Sci Vitaminol (Tokyo) 2007, 53(2):166-173.

59. Kwon O, Eck P, Chen S, Corpe CP, Lee JH, Kruhlak M, Levine M: Inhibition of the intestinal glucose transporter GLUT2 by flavonoids. FASEB J 2007, 21(2):366-377

60. Beckman JA, Creager MA, Libby P: Diabetes and atherosclerosis: epidemiology, pathophysiology, and management. JAMA 2002, 287(19):2570-2581.

61. Jeong SM, Kang MJ, Choi HN, Kim JH, Kim Jl: Quercetin ameliorates hyperglycemia and dyslipidemia and improves antioxidant status in type 2 diabetic db/db mice. Nutr Res Pract 2012, 6(3):201-207.

62. Negi $B$, Kaur R, Dey G: Protective effects of a novel sea buckthorn wine on oxidative stress and hypercholesterolemia. Food Funct 2013, 4(2):240-248.

63. Elbe H, Vardi N, Esrefoglu M, Ates B, Yologlu S, Taskapan C: Amelioration of streptozotocin-induced diabetic nephropathy by melatonin, quercetin, and resveratrol in rats. Hum Exp Toxicol 2014, 1-14. Epub ahead of print.

64. Chen P, Chen J, Zheng Q, Chen W, Wang Y, Xu X: Pioglitazone, extract of compound Danshen dripping pill, and quercetin ameliorate diabetic nephropathy in diabetic rats. J Endocrinol Invest 2013, 36(6):422-427.

65. Lai PB, Zhang L, Yang LY: Quercetin ameliorates diabetic nephropathy by reducing the expressions of transforming growth factor- $\beta 1$ and connective tissue growth factor in streptozotocin-induced diabetic rats. Ren Fail 2012, 34(1):83-87

66. Lassila M, Seah KK, Allen TJ, Thallas V, Thomas MC, Candido R, Burns WC, Forbes JM, Calkin AC, Cooper ME, Jandeleit-Dahm KA: Accelerated nephropathy in diabetic apolipoprotein e-knockout mouse: role of advanced glycation end products. J Am Soc Nephrol 2004, 15(8):2125-2138.

67. Xu S, Jiang B, Maitland KA, Bayat H, Gu J, Nadler JL, Corda S, Lavielle G, Verbeuren TJ, Zuccollo A, Cohen RA: The thromboxane receptor antagonist $\mathrm{S} 18886$ attenuates renal oxidant stress and proteinuria in diabetic apolipoprotein E-deficient mice. Diabetes 2006, 55(1):110-119.

68. Chan EC, Pannangpetch P, Woodman OL: Relaxation to flavones and flavonols in rat isolated thoracic aorta: mechanism of action and structure-activity relationships. J Cardiovasc Pharmacol 2000, 35(2):326-333.

69. Lodi F, Jimenez R, Moreno L, Kroon PA, Needs PW, Hughes DA, Santos-Buelga C, Gonzalez-Paramas A, Cogolludo A, Lopez-Sepulveda R, Duarte J, Perez-Vizcaino F: Glucuronidated and sulfated metabolites of the flavonoid quercetin prevent endothelial dysfunction but lack direct vasorelaxant effects in rat aorta. Atherosclerosis 2009, 204(1):34-39.

70. Schena FP, Gesualdo L: Pathogenetic mechanisms of diabetic nephropathy. J Am Soc Nephrol 2005, 16(Suppl 1):S30-S33.

71. Chavers BM, Bilous RW, Ellis EN, Steffes MW, Mauer SM: Glomerular lesions and urinary albumin excretion in type I diabetes without overt proteinuria. N Engl J Med 1989, 320(15):966-970.

72. Liu CM, Sun YZ, Sun JM, Ma JQ, Cheng C: Protective role of quercetin against lead-induced inflammatory response in rat kidney through the ROS-mediated MAPKs and NF-kB pathway. Biochim Biophys Acta 2012, 1820(10):1693-1703.
73. Dong YS, Wang JL, Feng DY, Qin HZ, Wen H, Yin ZM, Gao GD, Li C: Protective effect of quercetin against oxidative stress and brain edema in an experimental rat model of subarachnoid hemorrhage. Int J Med Sci 2014, 11(3):282-290.

74. Tonini CL, Campagnaro BP, Louro LP, Pereira TM, Vasquez EC, Meyrelles SS: Effects of aging and hypercholesterolemia on oxidative stress and DNA damage in bone marrow mononuclear cells in apolipoprotein E-deficient mice. Int J Mol Sci 2013, 14(2):3325-3342.

75. Liu CM, Ma JQ, Sun YZ: Quercetin protects the rat kidney against oxidative stress-mediated DNA damage and apoptosis induced by lead. Environ Toxicol Pharmacol 2010, 30(3):264-271.

76. Ishikawa Y, Kitamura M: Anti-apoptotic effect of quercetin: intervention in the JNK- and ERK-mediated apoptotic pathways. Kidney Int 2000, 58(3):1078-1087.

77. Liu CM, Zheng YL, Lu J, Zhang ZF, Fan SH, Wu DM, Ma JQ: Quercetin protects rat liver against lead-induced oxidative stress and apoptosis. Environ Toxicol Pharmacol 2010, 29(2):158-166.

78. Boots AW, Haenen GR, Bast A: Health effects of quercetin: from antioxidant to nutraceutical. Eur J Pharmacol 2008, 585(2-3):325-337.

doi:10.1186/1476-511X-13-184

Cite this article as: Gomes et al:: Renoprotective, anti-oxidative and antiapoptotic effects of oral low-dose quercetin in the C57BL/6J model of diabetic nephropathy. Lipids in Health and Disease 2014 13:184.

\section{Submit your next manuscript to BioMed Central and take full advantage of:}

- Convenient online submission

- Thorough peer review

- No space constraints or color figure charges

- Immediate publication on acceptance

- Inclusion in PubMed, CAS, Scopus and Google Scholar

- Research which is freely available for redistribution 